these defects should be corrected or not. As some of them disappear when the patient has worn the glasses which correct his refractive errors for some time, I personally do not correct them to start with. But if a patient who has given his glasses a good trial-say six weeks or morestill complains of eye-strain, and especially if he is troubled with diplopia, I retest with the Maddox rods and consider the question of prescribing prisms.

If the patient is over 40 he should now be tested with the near types to see what addition, if any, is necessary for near work. It is very important to find out exactly at what distance the patient wants to see-a short man with short arms will probably hold his book about 10 inches from his eyes; patients of another build will prefer it 13 inches away or even more; while a pianist requires vision at about 20 inches, and a laundress ironing at a table may want even more. The near vision addition would, of course, be different in each of these cases.

The chief mistake to avoid is giving the patient too strong an addition for close work. If you test the patient with a strong light behind him shining on the near types he is very likely to take a stronger lens than he requires, and he will probably complain when he comes to try the glasses afterwards that he feels they are "tearing the eyes out of his head." As a rough working rule for the patient who reads at 13 inches, the usual distance, we add +0.5 at $45 ;+1.75$ at $50 ;+2$ at $55 ;$ and +2.25 at 60 -he should never require any stronger addition than this to his distance glasses.

At the same time it should not be forgotten that a patient after 50 gradually develops an acquired hypermetropia, so that his distance glasses require gradual strengthening. A man who is emmetropic at 50 may require as much as +2.25 spheres for distance when he reaches the age of 80 , and, of course, his near glasses will have to be correspondingly strengthened. The point I wish to emphasize is that the addition to his distance correction for reading at 13 inches should probably never be greater than 2.25 at any age, with the possible exception of myopic eyes, as in them the range of accommodation is usually defective.

The next step, and a very important one, is to measure the distance between the patient's eyes both for distance and for near vision. The patient should wear his correcting lenses during this test and should, of course, fix a distant object.when he is wearing his distance glasses, and a near when he is wearing his near glasses.

The patient is now ready for his prescription. One of the snags in writing this is, that there is so much confusion in the way the angles of cylinders are marked. The standard method is to make the left side of each of the patient's eyes as you look at him zero, and measure the degrees from that counter-clockwise. But you will find trial frames and prescription fornis marked in all sorts of ways-zero sometimes at the temporal, sometimes at the nasal side of each eye; sometimes at the temporal side of one and the nasal of the other. If you have not a prescription form with a diagram on which you can mark the angle it is always advisable, after writing the strength of your cylinders and the degrees of the angle, to draw a horizontal line and then draw a line from one end of this to show roughly in what direction the angle is to be measured.

Before the patient goes you should give instructions as to whether the glasses are to be worn constantly or not; you should warn the patient (unless you have prescribed periscopic lenses) that he must learn to turn his head when he wants to see anything to the side, so that he always looks through the centre of his glasses; hypermetropes and anisometropes should be warned that they may require some weeks of constant wear before the glasses become comfortable; patients who are given cylinders at an angle for the first time should be warned that at first they will be troubled by straight lines not in the direct line of vision appearing distorted; while all patients, but especially children, should be advised to take their spectacles to the optician from time to time to make sure that the frames have not got twisted.

The fina! point is to insist that the glasses should be sent to you to be checked before the patient wears them. I have learnt the necessity of this by repeated painful experience. I have had patients complaining that the glasses did not suit them in whom I have found the axes of the cylinders the opposite way to my prescription. I had a patient once for whom I took the trouble to work out a formula for periscopic lenses for use while playing tennis. It was only two years afterwards, when he came to see me about something else, that I found the glasses had been useless, and on examining them found the opticians had disregarded my formula and sent him ordinary spheres; I have had patients with anisometropia in whom the strong lens had been put opposite the eye that required the weaker. But the thing in which I find the greatest difficulty is in getting the lenses centred correctly. The oculist finds a frame that fits nicely on the patient's nose and looks neat, and he will often fit the lenses into this without any regard to the interpupillary distance. Glasses undoubtedly look neater when the lenses are not very wide apart, and there is no objection to the optician using such frames so long as he decentres the lenses outwards so that the distance between the optical centres is correct, but so far I have never seen this done. Almost always, unless specially ordered otherwise, the optician fits lenses of which the optical and geometrical centres coincide, though $I$ have actually had a case in which the lenses were the correct distance apart, but for some obscure reason or other decentred lenses were fitted, bringing the optical centres much nearer than they should have been!

I lay stress upon this point because I believe a mistake in the centring of the lenses is often an unsuspected cause of eye-strain. This is not to be wondered at when you remember that a spherical lens whose optical centre is not opposite the centre of the pupil has the action of a prism. An error of only $4 \mathrm{~mm}$. (1/6 inch) in the distance between the optical centres of a pair of +5 spectacles will have the same effect as putting a No. 1 prism before each eye. When weak lenses are concerned the prismatic effect of wrong centring, if only a few millimetres out, does not matter much; but when you have to prescribe strong lenses in either hypermetropia or myopia it is very important to satisfy yourself that the optical centres are exactly the right distance apart.

\section{THE TREATMENT OF SEA-SICKNESS. BY}

VINCENT MOXEY, M.R.C.S., L.R.C.P., SURGEON, ROYAL MAIL STEAM PACKET COMPANY.

RecentuY, in a brief but fairly exhaustive review of the various theories of the causation of sea-sickness, Ribolla points out that overstimulation of the vestibular nerve, with consequent irritation of the vagus, best meets the case. As he shows, sea-sickness presents the syndrome that may be observed in sensitive subjects on excitation of the vestibular nerve by the simple injection of warm or cold water into the external auditory meatus, or by means of a mild voltaic current. Perhaps the most exhaustive account of the part played by the semicircular canals in motionsickness is that of $\mathbf{J}$. Byrne, ${ }^{2}$ which is extremely valuable for reference. Sea-sickness is not an affection sui generis, but a particular form of motion sickness, other variations of which are the nauseas associated with aeroplanes, trains, swings, roundabouts, waltzing, etc.

The part played by the internal ear has been recognized for many years ${ }^{3}$ and may now be regarded as fully accepted. Portier's recently gave a very good description, with diagrams, of the nervous mechanism involved. Pozerski at the Pasteur Institute, studying what Weiss calls " ce petit accident des traversées," induced it experimentally in animals by means of an apparatus capable of producing rolling and pitching motions. Several interesting points emerged. Fasting animals were found less susceptible than recently fed ones; many kinds were quite immune, and others soon acquired immunity. As showing the psychological factor, a dog, after the first experiment, on being brought into the room was sick at the mere sight of the machine.

In addition to anticipation and dread, other factors such as optic vertigo-as pointed out by Erasmus Darwin, 
Hewitt, and Wilson Fox-agitation of the abdominal viscera, etc., play subsidiary parts. Quite young infants and very old people are generally immune, as might bo expected in a functional nervous condition, such as seasickness is. To explain the relative immunity of babies the state of the thymus and endocrine glands has been suggested. ${ }^{7}$ This seems unnecessary. Further, Bédart and others affirm that deaf-mutes are not susceptible to motionsickness. Sir T. Lauder Brunton ${ }^{8}$ held the view that the origin was a mixed one. He also gave the most practical detailed and helpful advice as to treatment that I have yet met with:

As a working hypothesis, then, let us take it that the vomiting centre is overstimulated by centripetal impulses, preponderatingly vestibular, but not exclusively so. Rational treatment at once becomes obvious: Diminish the activity of the vomiting centre by means of chloral and bromides, or else lessen the conductivity of the vagus by the administration of atropine.

The atropine method is at present that most in farour, but it has not been satisfactory in my experience, and is certainly not free from danger and unpleasantness. Incidentally, the use as a routine method of this potent drug, either hypodermically or by mouth, in a crowded ship, is not easy. Portier states that hyoscyamine, the left isomer of atropine, is not more toxic and has an activity twice as great. Morphine is not much in favour. On one voyage, however, before $I$ adopted routine rectal treatment, as described later, it seemed to me to have saved the life of a young woman, who vomited from Suez to Calcutta save when under its influence.

Many years ago, crossing the Western Ocean to Canada in bad weather, it became clear to me-from painful personal experience-that chloral in the form of syrup was of the greatest value. But even so slightly unpleasant a preparation as this is impossible to a sea-sick personjust when most needed. It is speedily rejected. Brunton was right in teaching that chloral and bromide, properly used, would, practically at all events, prevent all suffering. The only difficulty is the administration and retention of the drugs. This is easily met by giving them per rectum. Last year, on the North Atlantic, the opportunity for trying this on a large scale occurred: the results were most gratifying. A solution, however, of this kind cannot be left to the unskilled steward or attendant, so I had to make a suitable suppository.

The incorporation of the drugs in the form of a suppository presented considerable difficulty, as the usual bases were quite unsuitable. Messrs. Allen and Hanburys, Itd., have now prepared suppositories which stand the tropics perfectly. I possess some that have crossed the equator four times, and never left the cabin for the icechest. In the rectum they melt readily, absorption is rapid, and no irritation locally appears to follow their use. Two suppositories contain 15 grains of chloral and 30 grains of bromide. These are not large doses : 30 grains of chloral at a dose in a milk enema, two or three times daily, is spoken of as being used by $\mathrm{Mir}^{9}$ in the vomiting of pregnancy-in many ways related to sea-sickness; and, as a sedative in other nerve conditions 2 or even 3 grams. ${ }^{10} 11$ Such large doses are not within my experience. It is clear, however, that there is no risk in a frequent repetition of small doses. Subsidiary measures should not bo neglected. These are recumbency (in bunk in cabin is the best), warmth, keeping the eyes shut, and the use of an abdominal belt. The ideal position for a bunk, where it is possible, would be amidships, on the main deck level-lying fore and aft in the centre of the ship, with the feet pointing to the bow. This is seldom attainable; but the opposites can be avoided. Still, with suitable dosage on the lines mentioned above, such points become of minor import.

This treatment, which I have found so valuable, possesses important advantages over oral methods of administration: (1) The therapeutic action of the drugs is certain, because no gastric disturbance can interfere with it. (2) Absorption of the drug is more certain, and the effect is prolonged. (3) It causes no gastrio disturbance such as occasionally results from the use of other remedies for seasickness.
The best results are obtained by using the suppositories in the following manner: As a preventive, one should be inserted morning and erening for the first three days at sea. If the patient is sick when first seen a suppository should be administered at once, and repeated every two or three hours, as required, for four doses. If the sea passage is short, a suppository should be used three hours before going on board, and again before the ship starts. There is no danger whatever provided the administration is stopped when sommolence supervenes.

1. Ribolla: Patogenesi e Terapia del Mal di Mare, Giorn. di Med. Militare, Roma, November, 1922

2 Byrne: Physiology of the Semi-cirsular Canals and their Relations to Sea-sickness, H. K. Lewis, London, 1912

3 Casanet: Estudio etiologico del mareo, Rev. espec. Med Madrid, 1903 Terbocal : Le mal de mer et l'oreille interne, Vie mé. Paris, 1923, Napoli, 1922, 111, 281-86. s poli, 1922, 111, 281-86.

S Portier : Le mal de mer (mécanisme physiologique, traitement), Rev. cient., Paris, 1923, lxi, 353

E. Weiss: La Nature, March 25th, 1922.

Traitement du mal de mer, Presse Ḿ'd. Paris, 1923.

Brunton: Lectures on the Actions of Medicines, 1897.

L. Mir : Diagnostico etiologico y tratamiento de los vomitos del emrazo, Revista de Med. y Cirug. de la Habana, November 25th, 1923.

Jochmann: Handbuch der inn. Med., vol. i, 797

11 Oddo: La medicina de urgencia, p. 659. Magnan's method of giving large doses of chloral and bromide.

\section{CURE OF UTERINE PROLAPSE BY RE-EDUCATION OF THE MUSCLES CONSTRICTING THE VAGINA. \\ BY}

T. STACEY WILSON, M.D., F.R.C.P.,

HONORARY CONSULTING PHYSICIAN, BIRMINGHAM GENERAL HOSPITAL.

THE muscles which close the vagina (in common with other muscles whose physical relationships are greatly changed during pregnancy and parturition) are liable to lose their normal habit of tonic contraction after the cessation of the distension to which they have been temporarily subjected. When the "vaginal" muscles are subject to this loss of tone, prolapse of the uterus is liable to follow, and if the support normally given by the vaginal sphincter and the fibrous tissues associated with it be lost (owing to the parts being torn during parturition) the liability to uterine prolapse is greatly increased.

If the tone of these muscles which tend to occlude the vagina be tested in a case of uterine prolapse it is usually found to be decidedly poor, and in extreme cases the laxity of the vagina may be so considerable that no form of pessary can be retained. Fortunately, however, although the habit of tonic contraction of these muscles be lost, the power of voluntary contraction is not as a rule also lost; and when during a vaginal examination the patient is told to contract, so far as she is able, the muscles of the pelvic floor, it is found that some muscular compression is exerted upon the fingers in the vagina, either by the sphincter proper or by the other muscles which have the power of constricting it. Voluntary contraction of these muscles can be as a rule brought about by asking the patient to contract the sphincter and the levator ani, by "tightening herself up" as if she were endeavouring to control a sudden attack of diarrhoea.

When any voluntary control of these muscles is present the re-establishment of full tonic contraction is only a matter of time, for (as is the case with most muscles of this type) the frequent repetition of voluntary contraction soon restores a lost habit of tonio contraction. The patient's attention is therefore drawn to the fact that the vagina is tightening upon the examining fingers when she makes this special type of effort; and she is asked to make, and then to cease making, the effort several times in succession till she has a further knowledge of what is required of her. She is then told to contract these muscles of the pelvic floor many times during every hour of the day, and to maintain the contraction as long as she conveniently can. If these rules are carried out-as they easily can be-the muscles which diminish the lumen of the ragina will in a very few weeks greatly increase in vigour; so much so that within two or three weeks they will be able to grasp a singlo finger with more force than they could grasp two fingers at 